\title{
Desempenho de híbridos de milho submetidos a diferentes espaçamentos e densidades populacionais
}

\author{
Claudia Sousa Demétrio(1), Domingos Fornasieri Filho(1), Jairo Osvaldo Cazetta(1) \\ e Disnei Amélio Cazetta(1)
} (1)Universidade Estadual Paulista, Faculdade de Ciências Agrárias e Veterinárias, Via de Acesso Prof. Paulo Donato Castellane, s/nº,
CEP 14884-900 Jaboticabal, SP. E-mail: claudia_demetrio@hotmail.com, fornasieri@fcav.unesp.br, cazetta@fcav.unesp.br, cazetta@bol.com.br

Resumo - O objetivo deste trabalho foi avaliar a influência de espaçamentos entre linhas e densidades populacionais, nos componentes de produção e na produtividade de grãos, em dois híbridos de milho (Zea mays). O experimento foi conduzido na safra 2006/2007, em Latossolo Vermelho eutrófico típico, textura argilosa, em Jaboticabal, SP. O delineamento experimental de blocos ao acaso foi composto por 24 tratamentos com parcelas subsubdivididas. As parcelas principais foram constituídas por três espaçamentos entre linhas $(0,40,0,60 \mathrm{e} 0,80 \mathrm{~m})$, as subparcelas, por dois híbridos e as subsubparcelas, por quatro densidades populacionais (30 mil, 50 mil, 70 mil e 90 mil plantas por hectare). Foram avaliadas as variáveis: altura de planta e altura da inserção da primeira espiga, diâmetro de colmo, número de grãos por espiga, massa de 1.000 grãos, produtividade de grãos e índice de colheita. A produtividade do milho aumentou com a redução do espaçamento entre linhas para os híbridos avaliados. O incremento na densidade populacional de milho resultou em aumentos na altura das plantas e na altura da inserção da primeira espiga e em redução do número de grãos por espiga. O melhor arranjo de plantas para os híbridos avaliados é de $0,40 \mathrm{~m}$ de espaçamento entre linhas e de 75 mil e 80 mil plantas por hectare de densidade populacional.

Termos para indexação: Zea mays, adensamento, arranjo espacial de plantas, componentes de produção, produtividade de grãos.

\section{Performance of maize hybrids submitted to different row spacing and population densities}

\begin{abstract}
The objective of this work was to evaluate the influence of row spacing and population densities on yield and yield components of two maize (Zea mays) hybrids. The experiment was carried out in the agricultural year 2006/2007, in a Typical Haplustox, in a clay texture soil, in Jaboticabal, SP, Brazil. The experimental design was a randomized complete block, with split-split plot with 24 treatments. The main plots were three row spacings $(0.40,0.60$ and $0.80 \mathrm{~m})$, the split-plots were two hybrids, and the split-split plots were four population densities $(30,000,50,000,70,000$ and 90,000 plants per hectare). The following variables were evaluated: plant height, first ear height, stem diameter, number of grains (kernels) per ear, mass of 1,000 grains, grain yield and harvest index. Maize grain yield increased with the reduction of row spacing for the evaluated hybrids. The increase of maize populational density resulted in increases of plant and first ear heights and in decrease of the number of grains per ear. The best planting arrangement for both hybrids was $0.40 \mathrm{~m}$ row spacing and 75,000 and 80,000 plants per hectare.
\end{abstract}

Index terms: Zea mays, plant density, spatial plant arrangement, production components, grain yield.

\section{Introdução}

Entre as práticas e técnicas empregadas para a obtenção de maior produtividade de milho (Zea mays L.), a escolha do arranjo espacial de plantas na área é uma das mais importantes (Almeida et al., 2000). Em razão disso e do surgimento de novos genótipos, numerosos estudos têm sido realizados para a determinação do melhor arranjo espacial de plantas de milho. No entanto, os resultados encontrados variam em razão do tipo e fertilidade do solo, disponibilidade hídrica, luminosidade, híbridos, adubações e manejo empregado (Penariol et al., 2003). Para Argenta et al. (2001), justifica-se reavaliar as recomendações de espaçamento entre linhas e densidade de semeadura de milho em virtude das modificações introduzidas nos genótipos mais recentes, tais como: menor estatura de plantas e altura de inserção de espiga, menor esterilidade de plantas, menor duração do subperíodo

Pesq. agropec. bras., Brasília, v.43, n.12, p.1691-1697, dez. 2008 
pendoamento-espigamento, angulação mais ereta de folhas e elevado potencial produtivo.

A cultura do milho é tradicionalmente implantada no Brasil com espaçamentos entre linhas de 0,80 e $0,90 \mathrm{~m}$, o que possibilita adequado funcionamento dos equipamentos tradicionais à semeadura, tratos culturais e colheita (Mattoso et al., 2006). A tendência atual é a redução do espaçamento entre linhas, de forma a modificar o comportamento da planta e interferir na eficácia de utilização dos recursos do meio, mantendose a densidade de plantas constante. A redução do espaçamento entre linhas, tem como vantagens $\mathrm{o}$ incremento na distância entre as plantas na linha, proporcionando um arranjo mais eqüidistante dos indivíduos na área de cultivo, o que possibilita redução na competição entre as plantas por água, por luz e nutrientes (Porter et al., 1997; Alvarez et al., 2006), limitando, por sua vez, o desenvolvimento de plantas daninhas, pela redução de transmissão de luz no dossel vegetal (Balbinot \& Fleck, 2005).

Entre as formas de manipulação do arranjo de plantas, a densidade populacional é a que tem maior efeito no rendimento de grãos de milho, já que pequenas alterações na população implicam modificações relativamente grandes no rendimento final (Silva et al., 2006). O incremento na densidade de plantas é uma das formas mais fáceis e eficientes de se aumentar a interceptação da radiação solar incidente pela comunidade de plantas de milho. No entanto, o uso de densidades muito elevadas pode reduzir a atividade fotossintética da cultura e a eficiência da conversão de fotoassimilados em produção de grãos. Em conseqüência disso, há um aumento de esterilidade feminina e redução do número de grãos por espiga e do rendimento de grãos (Marchão et al., 2006). Assim, sendo a densidade populacional ótima, para um determinado híbrido, corresponde ao menor número de plantas por unidade de área, o que induz à maior produtividade.

Atualmente, nos programas de melhoramento de milho, têm-se buscado genótipos com elevada resposta produtiva em elevadas densidades populacionais, de 80 mil a 100 mil plantas por hectare, e sob espaçamentos entre linhas mais reduzidos (Dourado Neto et al., 2003).

Dessa maneira, a combinação do espaçamento entre as linhas e o número de plantas por metro tem sido discutida com maior freqüência pela maior ou pela menor adaptação da cultura ao ambiente - decorrente das variações morfológicas e genéticas apresentadas pelos híbridos atuais -, como forma de maximizar a produção de grãos pela otimização do uso de fatores de produção, como: água, luz e nutrientes disponíveis num agroecossistema (Dourado Neto et al., 2003), melhor distribuição das raízes e redução das amplitudes térmicas na camada superficial do solo, nos estádios iniciais de desenvolvimento (Sharrat \& McWilliams, 2005).

O objetivo deste trabalho foi avaliar a influência de diferentes espaçamentos entre linhas e densidades populacionais no desempenho de dois híbridos de milho, com ênfase nos componentes do rendimento e na produtividade.

\section{Material e Métodos}

O experimento foi conduzido em condições de campo, na Fazenda Experimental da Unesp, Faculdade de Ciências Agrárias e Veterinárias, Campus de Jaboticabal, em Latossolo Vermelho eutrófico típico, textura argilosa, A moderado. A área experimental está situada a $21^{\circ} 15^{\prime} 22^{\prime \prime} \mathrm{S}$, e $48^{\circ} 18^{\prime} 58^{\prime \prime} \mathrm{W}$, e a uma altitude de $605 \mathrm{~m}$. O clima da região, segundo classificação de Köppen, é de transição entre os tipos Cwa (Clima tropical de altitude com inverno seco e verão úmido) e Aw (Tropical chuvoso com inverno seco).

Antes da instalação do experimento, foram coletadas amostras de solo deformadas da área experimental na camada de $0-20 \mathrm{~cm}$, e realizada a análise química do solo, com os resultados: $\mathrm{pH}$ em $\mathrm{CaCl}_{2}$ de 5,2; $25 \mathrm{~g} \mathrm{dm}^{-3}$ de $\mathrm{MO} ; 39 \mathrm{mg} \mathrm{dm}^{-3}$ de $\mathrm{P}$ resina; $26 \mathrm{mmol}_{\mathrm{c}} \mathrm{dm}^{-3}$ de $\mathrm{K} ; 10 \mathrm{mmol}_{\mathrm{c}} \mathrm{dm}^{-3} \mathrm{de} \mathrm{Ca}$; $31 \mathrm{mmol}_{\mathrm{c}} \mathrm{dm}^{-3}$ de $\mathrm{Mg} ; 41,4 \mathrm{mmol}_{\mathrm{c}} \mathrm{dm}^{-3}$ de $\mathrm{H}+\mathrm{Al}$; $72,4 \mathrm{mmol}_{\mathrm{c}} \mathrm{dm}^{-3}$ de SB; 5,4 $\mathrm{mmol}_{\mathrm{c}} \mathrm{dm}^{-3}$ de CTC; e $57,2 \%$ de V.

O delineamento experimental utilizado foi o de blocos ao acaso, com parcelas subsubdivididas com 24 tratamentos e três repetições. As parcelas principais foram constituídas por três espaçamentos entre linhas $(0,40,0,60$ e $0,80 \mathrm{~m})$; as subparcelas, por dois híbridos simples (P30K73 e P30F80) e as subsubparcelas, por quatro densidades populacionais $(30 \mathrm{mil}, 50 \mathrm{mil}$, 70 mil e 90 mil plantas por hectare).

Foram utilizados os híbridos simples de milho com características de plantas modernas, um com germoplasma basicamente de clima temperado (P30K73) e outro de clima tropical (P30F80), ambos 
de ciclo semiprecoce, com alta defensividade perante as principais doenças e com elevado potencial produtivo, recomendados para o Estado de São Paulo nas condições de Centro Baixo.

No espaçamento de $0,40 \mathrm{~m}$ entre linhas, cada parcela com $24 \mathrm{~m}^{2}$ foi constituída de 12 linhas de $5 \mathrm{~m}$ de comprimento, sendo consideradas para avaliação as oito linhas centrais; no espaçamento de $0,60 \mathrm{~m}$ entre linhas, cada parcela com $24 \mathrm{~m}^{2}$ foi constituída de oito linhas de $5 \mathrm{~m}$ de comprimento, sendo consideradas para avaliação as seis linhas centrais; e no espaçamento de $0,80 \mathrm{~m}$ entre linhas, cada parcela com $24 \mathrm{~m}^{2}$ foi constituída de seis linhas de $5 \mathrm{~m}$ de comprimento, sendo consideradas para avaliação as quatro linhas centrais, excluindo-se, em cada espaçamento, $1 \mathrm{~m}$ de cada extremidade.

A adubação de semeadura do milho foi constituída de $7 \mathrm{~kg} \mathrm{ha}^{-1}$ de $\mathrm{N}$ e $70 \mathrm{~kg} \mathrm{ha}^{-1}$ de $\mathrm{P}_{2} \mathrm{O}_{5}$ e $\mathrm{K}_{2} \mathrm{O}$ (fórmula 2-20-20), com base nas características químicas do solo e considerando a produtividade máxima esperada de 10 a $12 \mathrm{Mg} \mathrm{ha}^{-1}$ (Raij \& Cantarella, 1997).

O preparo do solo foi realizado por meio de uma gradagem com grade pesada, uma aração com aivecas e gradagem com grade niveladora, sendo a semeadura efetuada manualmente nos sulcos previamente adubados mecanicamente. A quantidade de plantas por unidade de área foi relacionada com a quantidade de sementes utilizadas e com a sua distribuição na linha, utilizandose duas sementes por cova. O desbaste foi realizado aos 15 dias após semeadura, garantindo-se o número de plantas e a sua distribuição espacial correspondente à população dos respectivos tratamentos.

A adubação de coberturas foi realizada no estádio de cinco folhas com a aplicação de $50 \mathrm{~kg} \mathrm{ha}^{-1}$ de $\mathrm{N}$ e de $\mathrm{K}_{2} \mathrm{O}$ (fórmula 20-0-20) e com 70 e $84 \mathrm{~kg} \mathrm{ha}^{-1}$ de $\mathrm{N}$ e de $\mathrm{S}$, respectivamente, na forma de sulfato de amônio, no estádio de oito folhas.

As plantas foram mantidas em condições ideais de sanidade, fazendo-se o controle de insetos-praga, doenças foliares e de plantas invasoras. O controle de plantas invasoras foi realizado na pré-emergência, com a aplicação de $1.125 \mathrm{~g} \mathrm{ha}^{-1}$ do princípio ativo atrazina em pré-emergência do milho, e, posteriormente, com capina manual. Para o controle de insetos-praga, em especial de lagarta-do-cartucho, foram realizadas aplicações com os princípios ativos de $384 \mathrm{~g} \mathrm{ha}^{-1}$ de cloropirifós, $10 \mathrm{~g} \mathrm{ha}^{-1}$ de deltametrina e $288 \mathrm{~g} \mathrm{ha}^{-1}$ de cloropirifós $+15 \mathrm{~g} \mathrm{ha}^{-1}$ de lufenuron, aos 11, 18 e 31 dias após semeadura, respectivamente.
No decorrer do período experimental foram feitas as seguintes avaliações: altura das plantas - distância entre a superfície do solo e a extremidade da inflorescência masculina; altura de inserção da primeira espiga distância entre a superfície do solo e a inserção da espiga superior; diâmetro do colmo - determinado no primeiro entrenó acima do colo da planta; número de grãos por espiga; massa de 1.000 grãos; produtividade de grãos; índice de colheita - relação entre a produção de matéria seca de grãos e a produção de matéria seca total da planta (menos raízes). Os caracteres altura de planta, altura de inserção da primeira espiga e diâmetro do colmo foram determinados com base em uma amostragem de cinco plantas, coletadas na área útil de cada subparcela. Para determinar o número de grãos por espiga e massa de 1.000 grãos, foram coletadas dez espigas em cada subparcela. As avaliações que envolveram pesagem de grãos foram corrigidas para $13 \%$ de umidade.

Os resultados obtidos foram submetidos à análise de variância pelo teste $\mathrm{F}$. As médias das variáveis qualitativas foram comparadas pelo teste de Tukey, e as médias das variáveis quantitativas foram submetidas à análise de regressão polinomial, quando necessário.

\section{Resultados e Discussão}

A altura da planta e da inserção da primeira espiga na planta não foram influenciadas pela diminuição do espaçamento entre linhas (Tabela 1). Martins \& Costa (2003) também não obtiveram alterações em ambos os componentes com a diminuição do espaçamento entre linhas de $0,90 \mathrm{~m}$ para $0,45 \mathrm{~m}$; entretanto, Penariol et al. (2003) e Alvarez et al. (2006) observaram incremento na altura de plantas e da primeira espiga com a redução do espaçamento entre linhas.

Os híbridos P30K73 e P30F80 diferiram entre si, em relação à altura da planta, e responderam de forma linear positiva nesse componente, com o aumento da densidade populacional (Figura 1 A), com o P30K73 respondendo de forma mais intensa ao incremento populacional. Com relação à altura de inserção da primeira espiga não se verificou diferenças entre os híbridos, obtendo-se com o aumento da densidade populacional, incrementos na altura de inserção (Tabela 1). Da mesma forma, Argenta et al. (2001) e Alvarez et al. (2006) observaram maiores alturas de plantas e de inserção da espiga com o aumento 
da densidade populacional, sugerindo uma tendência natural de aumento de altura de plantas em situações de alta densidade. Segundo Sangoi et al. (2002) e Argenta et al. (2001), a altura das plantas será tanto maior quanto maior a população, devido ao efeito combinado da competição intra-específica por luz, com conseqüente estímulo da dominância apical das plantas.

A redução do espaçamento entre linhas, de $0,8 \mathrm{~m}$ para $0,40 \mathrm{~m}$, não afetou o diâmetro do colmo das plantas de milho (Tabela 1). No entanto, essa variável apresentou diferenças significativas quanto ao híbrido e quanto à densidade populacional. $\mathrm{O}$ aumento da densidade de plantas, de 30 mil para 90 mil plantas por hectare, provocou diminuição do diâmetro de colmo (Tabela 1), o que está de acordo com Porter et al. (1997) e com Dourado Neto et al. (2003) que observaram que quanto maior a densidade populacional menor o diâmetro do colmo. Segundo Gross et al. (2006), a densidade populacional interfere na massa individual das plantas, obtendo-se um decréscimo de matéria seca individual, nomeadamente do colmo, como resultado da competição entre elas pelos recursos do meio. Isto leva a inferir que as plantas tendem a ficar mais suscetíveis ao quebramento e/ou acamamento com o incremento populacional, havendo diferenças entre genótipos.

Em relação ao número de grãos por espiga, foram observadas interações entre densidade populacional e espaçamento entre linha e entre densidade populacional e híbridos (Tabela1). Verificou-se redução do número de grãos por espiga à medida que houve aumento na densidade populacional, a partir de 50 mil plantas por hectare, para todos os espaçamentos entre linhas (Figura 1 B). A redução foi mais acentuada nos espaçamentos de 0,40 e $0,60 \mathrm{~m}$, no entanto, essa diferença não foi significativa. Penariol et al. (2003) e Amaral Filho et al. (2005) também obtiveram redução no número de grãos por espiga com o aumento na densidade populacional de 40 mil para 80 mil plantas por hectare. Isso pode ter ocorrido em razão da melhor distribuição das plantas na área, o que possibilita a maximização da atividade fotossintética pós-antese. Dourado Neto et al. (2003) verificaram que, nas populações compreendidas entre 30 mil e 60 mil plantas por hectare, os genótipos de milho apresentaram incremento do comprimento de espiga

Tabela 1. Estatura da planta $(\mathrm{cm})$, altura da inserção da primeira espiga $(\mathrm{cm})$, diâmetro do colmo $(\mathrm{mm})$, número de grãos por espiga, massa de grãos por espiga (g), massa de 1.000 grãos (g), produtividade dos grãos $\left(\mathrm{kg} \mathrm{ha}^{-1}\right)$ e índice de colheita (\%) dos híbridos de milho P30K73 e P30F80, submetidos a diferentes espaçamentos entre linhas e densidades populacionais, na safra 2006/2007, em Jaboticabal, SP(1).

\begin{tabular}{|c|c|c|c|c|c|c|c|}
\hline Tratamento & $\begin{array}{c}\text { Altura da } \\
\text { planta }\end{array}$ & $\begin{array}{c}\text { Altura da } \\
\text { primeira espiga }\end{array}$ & $\begin{array}{c}\text { Diâmetro de } \\
\text { colmo }\end{array}$ & $\begin{array}{c}\text { Número de grãos } \\
\text { por espiga }\end{array}$ & $\begin{array}{c}\text { Massa de } \\
1.000 \text { grãos }\end{array}$ & $\begin{array}{c}\text { Produtividade } \\
\text { de grãos }\end{array}$ & $\begin{array}{c}\text { Índice de } \\
\text { colheita }\end{array}$ \\
\hline \multicolumn{8}{|l|}{ Espaçamento (E) } \\
\hline $0,40 \mathrm{~m}$ & 234 & 96 & 22,5 & 504 & 324 & $11.512 \mathrm{a}$ & 42 \\
\hline $0,60 \mathrm{~m}$ & 237 & 97 & 22,1 & 500 & 324 & $10.902 b$ & 43 \\
\hline $0,80 \mathrm{~m}$ & 234 & 94 & 22,6 & 512 & 313 & $10.297 \mathrm{c}$ & 41 \\
\hline Teste F & $0,35^{\text {ns }}$ & $0,30^{\text {ns }}$ & $0,43^{\mathrm{ns}}$ & $0,63^{\text {ns }}$ & $0,83^{\mathrm{ns}}$ & $145,0 * *$ & $1,78^{\mathrm{ns}}$ \\
\hline DMS & - & - & - & - & - & 254 & - \\
\hline \multicolumn{8}{|l|}{ Híbridos $(\mathrm{H})$} \\
\hline P30K73 & $239 a$ & 95 & $21,8 b$ & $493 b$ & $303 b$ & $10.733 b$ & $41 b$ \\
\hline P30F80 & $231 b$ & 98 & $22,9 \mathrm{a}$ & $517 \mathrm{a}$ & $337 \mathrm{a}$ & $11.074 \mathrm{a}$ & $44 a$ \\
\hline Teste F & $7,98^{*}$ & $3,10^{\mathrm{ns}}$ & $36,21 * *$ & $8,73^{*}$ & $73,5 * *$ & $9,74^{*}$ & $31,12^{* *}$ \\
\hline DMS & 6,81 & - & 0,48 & 19,5 & 9,75 & 267 & 1,68 \\
\hline \multicolumn{8}{|l|}{ Densidade populacional (D) } \\
\hline 30.000 plantas ha ${ }^{-1}$ & $224 d$ & $87 \mathrm{c}$ & $23,2 \mathrm{a}$ & $510 \mathrm{a}$ & $322 \mathrm{ab}$ & $6.561 d$ & 42 \\
\hline 50.000 plantas ha $^{-1}$ & $232 \mathrm{bc}$ & $94 b$ & $22,7 \mathrm{a}$ & $531 \mathrm{a}$ & $326 a$ & $10.608 \mathrm{c}$ & 43 \\
\hline 70.000 plantas $\mathrm{ha}^{-1}$ & $238 b$ & $99 \mathrm{ab}$ & $22,3 \mathrm{ab}$ & $518 \mathrm{a}$ & $327 \mathrm{a}$ & $13.488 \mathrm{a}$ & 42 \\
\hline 90.000 plantas ha $^{-1}$ & $246 \mathrm{a}$ & $104 \mathrm{a}$ & $21,4 b$ & $461 \mathrm{~b}$ & $306 \mathrm{~b}$ & $12.960 \mathrm{~b}$ & 42 \\
\hline Teste F & $49,2 * *$ & $30,3 * *$ & $7,99 * *$ & $28,10 * *$ & $4,41 * *$ & $568,5^{* *}$ & $0,45^{\mathrm{ns}}$ \\
\hline DMS & 5,17 & 4,94 & 1,03 & 21,8 & 17,8 & 504 & - \\
\hline Teste F (interação ExH) & $0,01^{\text {ns }}$ & $0,49^{\text {ns }}$ & $1,04^{\mathrm{ns}}$ & $1,45^{\mathrm{ns}}$ & $0,19^{\text {ns }}$ & $0,49^{\text {ns }}$ & $3,96^{\mathrm{ns}}$ \\
\hline Teste F (interação DxE) & $1,07^{\mathrm{ns}}$ & $1,19^{\text {ns }}$ & $2,18^{\mathrm{ns}}$ & $3,56 * *$ & $0,53^{\mathrm{ns}}$ & $2,33^{\mathrm{ns}}$ & $2,40^{*}$ \\
\hline Teste F (interação DxH) & $5,87 * *$ & $0,18^{\text {ns }}$ & $0,56^{\mathrm{ns}}$ & $3,96^{*}$ & $0,92^{\mathrm{ns}}$ & $4,80 * *$ & $2,11^{\mathrm{ns}}$ \\
\hline Teste F (interação DxExH) & $0,67^{\mathrm{ns}}$ & $0,73^{\text {ns }}$ & $0,78^{\text {ns }}$ & $2,05^{\text {ns }}$ & $0,46^{\mathrm{ns}}$ & $1,77^{\mathrm{ns}}$ & $0,23^{\text {ns }}$ \\
\hline CV $(\%)$ parcela & 5,81 & 14,22 & 8,47 & 7,35 & 10,13 & 2,27 & 8,22 \\
\hline CV (\%) subparcela & 5,03 & 7,25 & 3,70 & 6,70 & 5,28 & 4,25 & 6,92 \\
\hline CV (\%) subsubparcela & 2,45 & 5,72 & 5,13 & 4,81 & 6,15 & 5,15 & 6,80 \\
\hline
\end{tabular}


pela redução do espaçamento de 0,80 para $0,40 \mathrm{~m}$. Para populações acima de 65 mil plantas por hectare, isso não foi observado, provavelmente pela competição

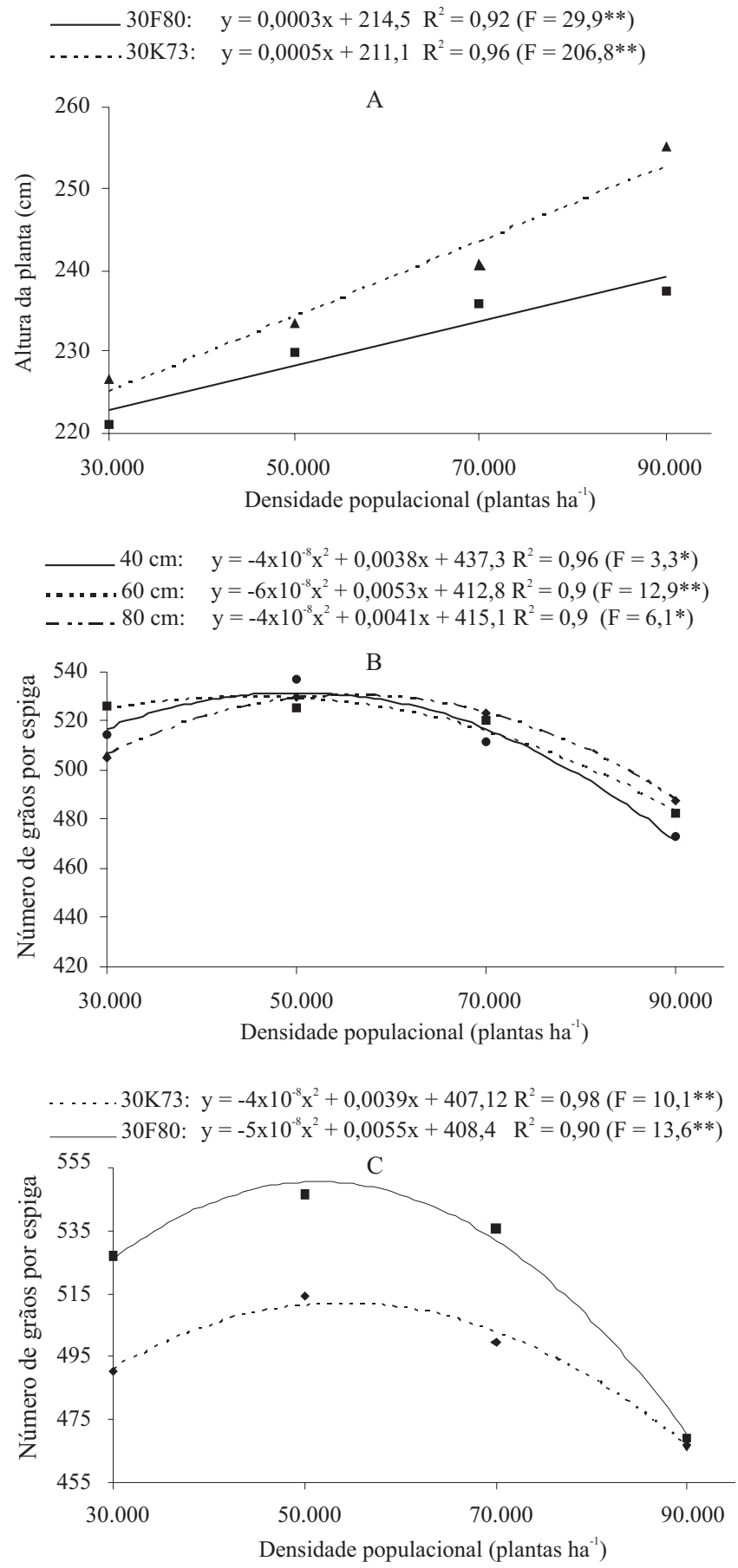

Figura 1. Altura da plantas para cada híbrido (A), número de grãos por espiga para cada espaçamento entre linhas (B) e número de grãos por espiga para cada híbrido (C), em razão de diferentes densidades populacionais, na safra 2006/2007, em Jaboticabal, SP. intra-especifica por água, nutrientes e luz superar os efeitos do melhor arranjo espacial entre plantas. Segundo Sangoi et al. (2000), plantas espaçadas eqüidistantemente competem minimamente por nutrientes, luz e outros fatores, favorecendo o melhor desenvolvimento das espigas.

Quanto à interação densidade populacional com os híbridos, o P30F80 apresentou maior número de grãos por espiga, tendo alcançado um máximo de 550 grãos por espiga, na população de $50 \mathrm{mil}$ plantas por hectare, enquanto que o híbrido P30K73 obteve 512 grãos por espiga na população de 55 mil plantas por hectare (Figura $1 \mathrm{C}$ ), sendo que ambos apresentaram características de não prolificidade, ou seja, apenas uma espiga comercial por planta. Em ambos os híbridos, até a população de plantas de 55 mil plantas por hectare, houve aumento do número de grãos na primeira espiga. A partir dessa população, o aumento da densidade populacional provocou a diminuição desse componente, indicando crescente competitividade por fotoassimilados, que são necessários para o crescimento reprodutivo, segundo Bruns \& Abbas (2005).

O espaçamento entre linhas não interferiu na massa de 1.000 grãos (Tabela 1). Amaral Filho et al. (2005), ao estudar espaçamento entre linhas, densidade populacional e adubação nitrogenada na cultura do milho, também não observaram diferenças na massa de 1.000 grãos e espaçamento entre linhas. No entanto, esse componente do rendimento foi influenciado pela densidade populacional e pelo genótipos. Populações de plantas de 50 mil a 70 mil plantas por hectare possibilitaram grãos mais pesados que os obtidos na população de 90 mil plantas por hectare. O híbrido P30F80 apresentou massa de 1.000 grãos superior à do híbrido P30K73.

A produtividade de grãos foi influenciada positivamente com a redução no espaçamento entre linhas (Tabela 1). O aumento da produtividade de grãos, com a redução do espaçamento entre linhas, é atribuído à maior eficiência na interceptação de radiação e ao decréscimo de competição por luz, água e nutrientes, entre as plantas na linha, devido a sua distribuição mais eqüidistante (Argenta et al., 2001). Esse componente apresentou ser dependente da interação entre densidades populacionais e híbridos, respondendo os genótipos de forma quadrática ao aumento da população de plantas, incrementando a 
sua produtividade de grãos na população entre 75 mil a 80 mil plantas por hectare. A partir dessa população observou-se diminuição da produtividade de grãos (Figura 2 A). Pela equação da curva do híbrido P30K73, determinou-se que a população de máxima eficiência técnica foi de aproximadamente 75 mil plantas por hectare, o que correspondeu à produtividade aproximada de $13 \mathrm{Mg} \mathrm{ha}^{-1}$; para o híbrido P30F80, a produtividade máxima foi de $14 \mathrm{Mg} \mathrm{ha}^{-1}$, com população máxima aproximada de 80 mil plantas por hectare. Verificou-se que a melhor adaptação e o maior potencial produtivo do híbrido $30 \mathrm{~F} 80$ contribuíram para a sua maior resposta de produtividade, no aumento da densidade populacional. Esses dados estão de acordo com estudos recentes que têm mostrado respostas positivas ao aumento da produtividade do milho pelo aumento da população de plantas, com produtividades máximas sendo atingidas com 70 mil a 80 mil plantas
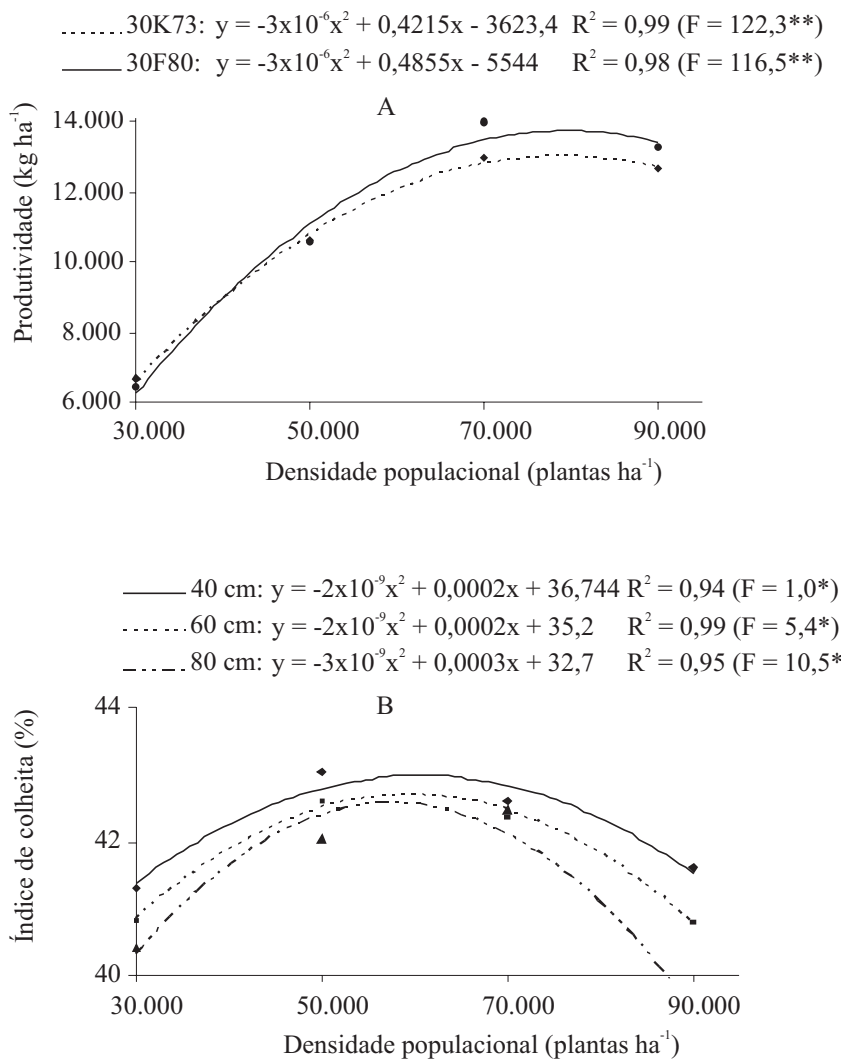

Figura 2. Produtividade de grãos para cada híbrido (A) e índice de colheita para cada espaçamento entre linhas (B), em razão da densidade populacional, na safra 2006/2007, em Jaboticabal, SP. por hectare, e diminuindo em populações mais elevadas (Dourado Neto et al., 2003; Martins \& Costa, 2003; Penariol et al., 2003; Resende et al., 2003; Flesch \& Vieira, 2004; Alvarez et al., 2006; Gross et al., 2006).

O índice de colheita - que representa a razão entre o rendimento biológico e a produtividade de grãos - é indicativo da eficiência com que a planta converte produção total de fitomassa acima do solo em produção total de parte colhida e comercializada da cultura (Martins \& Costa, 2003). Os valores de índice de colheita apresentados na Tabela 1 estão abaixo do considerado ideal (50 a 60\%), variando entre 40 e $44 \%$. Os baixos índices de colheita podem ter ocorrido devido à elevada precipitação pluvial e à reduzida luminosidade no período inicial do experimento, que contribuíram para o grande crescimento das plantas e a possíveis perdas da parte aérea da planta na colheita. No entanto obtiveram-se produtividades de grãos superiores a $10 \mathrm{Mg} \mathrm{ha}^{-1}$, compatíveis com sistemas de alta tecnologia.

Em relação à interação densidade populacional e espaçamento entre linhas, verificou-se que os índices de colheita mais elevados foram obtidos no espaçamento de $0,40 \mathrm{~m}$, embora sem diferença significativa, obtendose maximização com populações de 60 mil plantas por hectare nos espaçamentos de 0,40 e $0,60 \mathrm{~m}$, e de 58 mil plantas por hectare no espaçamento de $0,80 \mathrm{~m}$ (Figura $2 \mathrm{~B}$ ).

\section{Conclusões}

1. A produtividade do milho aumenta com a redução no espaçamento entre linhas para os híbridos avaliados.

2. O incremento na densidade populacional de milho aumenta a altura das plantas e da inserção da primeira espiga e reduz o número de grãos por espiga.

3. O melhor arranjo das plantas de milho para os híbridos avaliados é de $0,40 \mathrm{~m}$ de espaçamento entre linhas e de 75 mil e 80 mil plantas por hectare de densidade populacional.

\section{Agradecimentos}

À Universidade Estadual Paulista, Campus de Jaboticabal, pelas instalações oferecidas para desenvolvimento do trabalho; à Coordenação de Aperfeiçoamento de Pessoal de Nível Superior, por concessão de bolsas. 


\section{Referências}

ALMEIDA, M.L.; SANGOI, L.; ENDER, M. Incremento na densidade de plantas: uma alternativa para aumentar o rendimento de grãos de milho em regiões de curta estação estival de crescimento. Ciência Rural, v.30, p.23-29, 2000.

ALVAREZ, C.G.D.; PINHO, R.G.; BORGES, I.D. Avaliação de características agronômicas e de produção de forragens e grãos de milho em diferentes densidades de semeadura e espaçamentos entre linhas. Ciência e Agrotecnologia, v.30, p.402-408, 2006.

AMARAL FILHO, J.P.R. do; FORNASIERI FILHO, D.; FARINELLI, R.; BARBOSA, J.C. Espaçamento, densidade populacional e adubação nitrogenada na cultura do milho. Revista Brasileira de Ciência do Solo, v.29, p.467-473, 2005.

ARGENTA, G.S.; SILVA, P.R.F.; SANGOI, L. Arranjo de plantas em milho: análise do estado-da-arte. Ciência Rural, v.31, p.1075-1084, 2001.

BALBINOT, A.A.; FLECK, N.G. Benefício e limitações da redução do espaçamento entre linhas. Revista Plantio Direto, v.5, p.37-41, 2005.

BRUNS, H.A.; ABBAS, H.K. Ultra-high plant populations and nitrogen fertility effects on corn in the Mississippi valley. Agronomy Journal, v.97, p.1136-1140, 2005.

DOURADO NETO, D.D.; PALHARES, M.; VIEIRA, P.A.; MANFRON, P.A.; MEDEIROS, S.L.P.; ROMANO, M.R. Efeito da população de plantas e do espaçamento sobre a produtividade de milho. Revista Brasileira de Milho e Sorgo, v.2, p.63-77, 2003.

FLESH, R.D.; VIEIRA, L.C. Espaçamento e densidade de milho com diferentes ciclos no oeste de Santa Catarina, Brasil. Ciência Rural, v.34, p.25-31, 2004.

GROSS, M.R.; PINHO, R.G.; BRITO, A.H. Adubação nitrogenada, densidade de semeadura e espaçamento entre fileiras na cultura do milho em sistema de plantio direto. Ciência e Agrotecnologia, v.30, p.387-393, 2006.

MARCHÃO, R.L.; BRASIL, E.M.; XIMENES, P.A. Interceptação da radiação fotossinteticamente ativa e rendimento de grãos do milho adensado. Revista Brasileira de Milho e Sorgo, v.5, p.170-181, 2006.

MARTINS, P.E.; COSTA, A.J.A. Comportamento de um milho híbrido hiperprecoce em dois espaçamentos e diferentes populações de plantas. Cultura Agronômica, v.12, p.77-88, 2003.
MATTOSO, M.J.; GARCIA, L.C.; DUARTE, J.O.; CRUZ, J.C. Aspectos de produção e mercado do milho. Informe Agropecuário, v.27, p.95-104, 2006.

PENARIOL, F.G.; FORNASIERI FILHO, D.; COICEV, L.; BORDIN, L.; FARINELLI, R. Comportamento de cultivares de milho semeados em diferentes espaçamentos entre linhas e densidades populacionais, na safrinha. Revista Brasileira de Milho e Sorgo, v.2, p.52-60, 2003.

PORTER, P.M.; HICKS, D.R.; LUISCHEN, W.E.; FOND, J.H.; WARNES, D.D.; HOVERSTAD, T.R. Corn response to row width and plant population in the northern corn belt. Journal of Production Agriculture, v.10, p.293-300, 1997.

RAIJ, B. van; CANTARELLA, H. Recomendações de adubação e calagem de milho para grãos e silagem para o Estado de São Paulo. In: RAIJ, B. van; CANTARELLA, H.; QUAGGIO, J.A.; FURLANI, A.M.C. 2.ed. rev. atual. Campinas: Instituto Agronômico-Fundação IAC, 1997. p.56-59. (Boletim Técnico, 100).

RESENDE, S.G. de; PINHO, R.G.V.; VASCONCELOS, R.D. Influência do espaçamento entre linhas e da densidade de plantio no desempenho de cultivares de milho. Revista Brasileira de Milho e Sorgo, v.2, p.34-42, 2003.

SANGOI, L.; ENDER, M.; GUIDOLIN, A.F.; BOGO, A.; KOTHE, D.M. Incidência e severidade de doenças de quatro híbridos de milho cultivados com diferentes densidades de plantas. Ciência Rural, v.30, p.17-21, 2000.

SANGOI, L.; GRACIETTI, M.A.; RAMPAZZO, C.; BIANCHET, P. Response of Brazilian maize hybrids from different eras to changes in plant density. Field Crops Research, v.79, p.39-51, 2002.

SHARRAT, B.S.; McWILLIAMNS, D.A. Microclimatic and rooting characteristics of narrow-row versus conventional-row corn. Agronomy Journal, v.97, p.1129-1135, 2005.

SILVA, P.R.F.; SANGOI, L.; ARGENTA, G.; STRIEDER, M.L. Arranjo de plantas e sua importância na definição da produtividade em milho. Porto Alegre: Evangraf, 2006. 63p.

Recebido em 9 de janeiro de 2008 e aprovado em 18 de novembro de 2008 